\title{
Design of a tuned mass disc damper with variable natural frequency for chatter suppression
}

\author{
Christian Brecher ${ }^{1}$, Guifeng Zhao ${ }^{2}$, Marcel Fey ${ }^{3}$ \\ Laboratory for Machine Tools and Production Engineering, Aachen, Germany \\ ${ }^{2}$ Corresponding author \\ E-mail: ${ }^{1}$ C.Brecher@wzl.rwth-aachen.de, ${ }^{2}$ G.Zhao@wzl.rwth-aachen.de, ${ }^{3}$ M.Fey@wzl.rwth-aachen.de
}

Received 12 October 2020; received in revised form 26 October 2020; accepted 3 November 2020 DOI https://doi.org/10.21595/vp.2020.21755

Check for updates

Copyright $(\underset{C}{ } 2020$ Christian Brecher, et al. This is an open access article distributed under the Creative Commons Attribution License, which permits unrestricted use, distribution, and reproduction in any medium, provided the original work is properly cited.

\begin{abstract}
This paper presents a tuned mass disc damper (TMDD) for chatter suppression during metal cutting. The design utilizes the vibration of one cantilever beam. By the variation of the beam length, the natural frequency of the TMDD could be easily and accurately tuned to match the critical frequency of the primary structure. The damping effect of the TMDD is generated from the collision and the friction between the discs and the host structure, therefor it is essentially independent of the environment temperature and very durable.
\end{abstract}

Keywords: tuned mass damper (TMD), particle damper (PD), chatter suppression, frequency response function (FRF), impact hammer test.

\section{Introduction}

As Frederick Taylor has already stated in 1907, chatter is always one difficult problem in machining with machine tools [1]. It limits the productivity and harms the product quality [2]. Therefore, plenty of researchers are working on different chatter suppression methods such as passive damping techniques. Many passive damping methods could be used to suppress chatter in machining. The tuned mass damper (TMD) is one of them. The original idea of the TMD was introduced by Frahm in 1911 [3]. Another researcher Hahn has first proposed the use of the TMD as chatter suppression method [4]. The basic target of the TMD is to damp the critical mode of the machining systems [2]. In order to reach the aim, one natural frequency of the TMD must be tuned accurately to match the critical natural frequency of the machining systems [2]. The damping effect of the TMD is mostly realized by using the viscous materials, which are very sensitive to the external temperature and degrade over time [5,6]. Alternatively, the particle damper (PD) dissipates vibration energy by the collision and the friction between the particles and the hosting enclosure, therefor it is independent of the environmental temperature and very durable [6,7]. But the PD generates lower damping effect than the TMD at the same vibration level [5]. In order to avoid the drawbacks of the TMD and the PD, a few researchers have explored the tuned mass particle damper (TMPD), which combines the merits of the TMD and the PD $[5,8,9]$.

In this paper, we present a new passive damper, which combines the principles of the TMD and the PD. The particles are replaced by metal discs, therefore we name it tuned mass disc damper (TMDD). In the second section the structure of the TMDD is explained. Thereafter we present the measurements of the TMDD in the third section. Then we validate the effectiveness of the TMDD in the fourth section. At the end are the conclusion and the outlook.

\section{Structure of the TMDD}

Fig. 1 shows the design of the TMDD. It is attached to the primary structure through the magnetic foot with a M6 threaded hole. A M6 screw connects to the magnetic foot and works as one cantilever beam. The identical annular metal discs are installed on the M6 screw. The axial positions of the metal discs along the M6 screw are adjusted by changing the number of the front and back washers. The damping effect is generated by the collision and the friction between the metal discs and the M6 screw. The natural frequency of the TMDD depends on the total mass and 
the axial positions of the metal discs. The measurements of the natural frequencies will be explained in the next section.
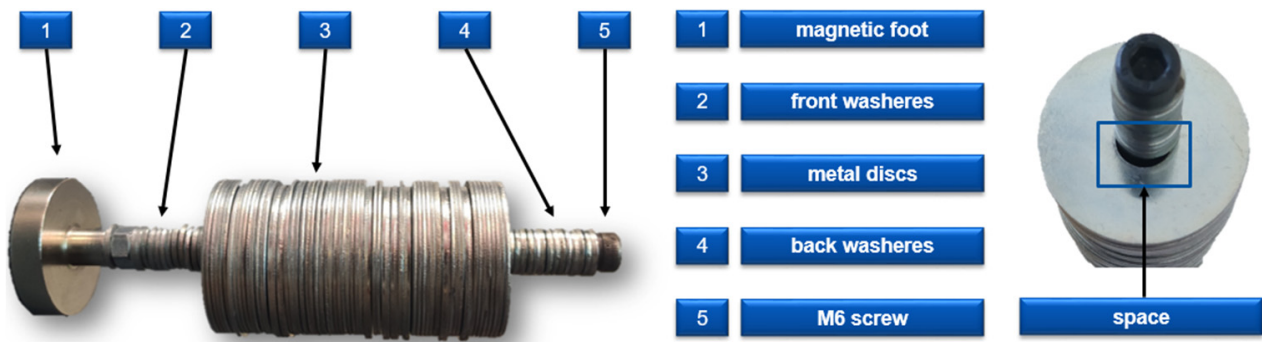

Fig. 1. Design of the TMDD

\section{Measurements of the TMDD}

As mentioned in the second section, the natural frequency of the TTMD could be adjusted by changing the total mass or the axial positions of the metal discs. During the measurements presented in this section, we kept the total mass of the metal discs as constant and varied their axial positions. The total number of the front and back washers was 30 . The number of the front washers increased from 1 to 29, while the number of back washers decreased from 29 to 1 . The natural frequencies of the TTMD with different axial positions of the metal discs were measured by the impact hammer tests. Because the mass of the accelerometer is very small compared to the total mass of the metal discs (small than $1.4 \%$ ), the natural frequency of the TMDD could be measured accurately. The measurement set up is shown in the Fig. 2.

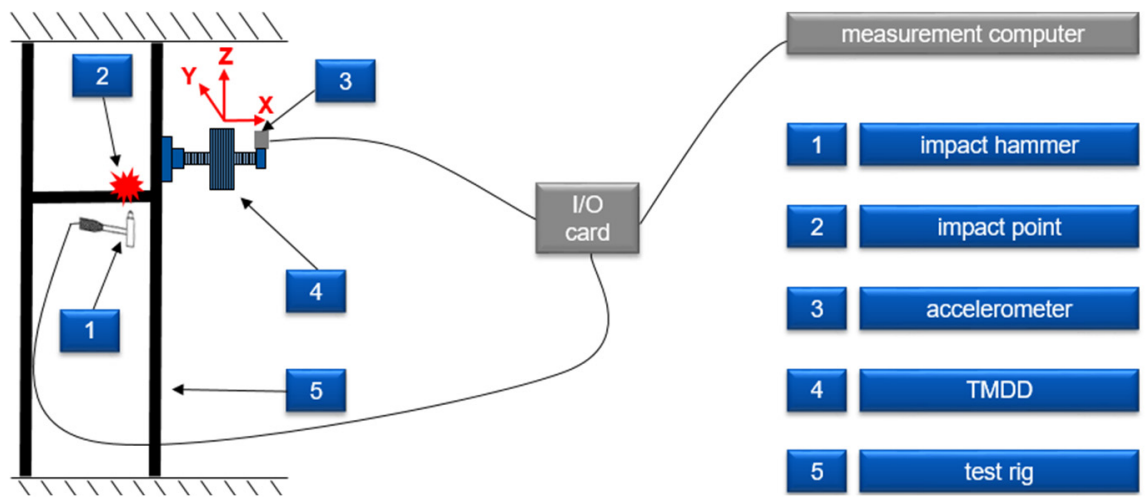

Fig. 2. Impact hammer test
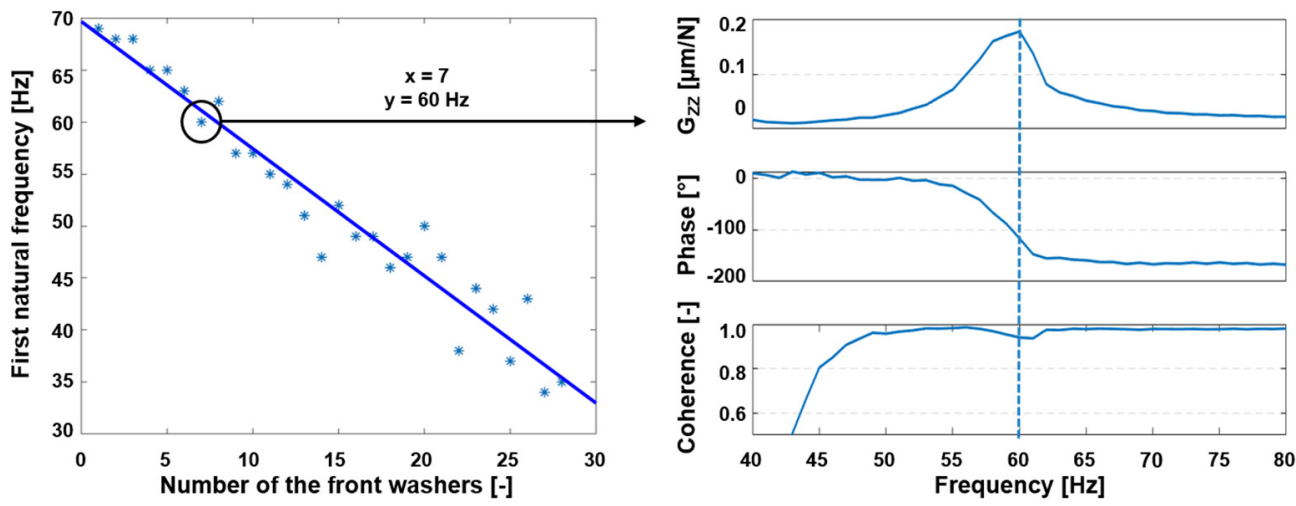

Fig. 3. Results of the impact hammer tests 
The results of the impact hammer tests are shown in the Fig. 3. The first natural frequency of the TTMD decreases from $69 \mathrm{~Hz}$ to $34 \mathrm{~Hz}$ with the increasing of the number of the front washers. This tendency is expected, because the M6 screw works as a cantilever beam, the length of the beam is proportional to the number of the front washers. The natural frequency of the TMDD out of this range could be reached by using another screw or changing the number of the metal discs. The measurement results would be used in the next section.

\section{Validation with a $\mathrm{z}$-slide test rig}

Because the z-slides of some milling machine tools are long overhanging, they have small dynamic stiffness. Which means chatter could easily occurs during the machining processes with these machine tools. In this section, we present the validation for the TMDD with a z-slide test rig. As shown in the Fig. 4, the z-slide has the mass $410 \mathrm{~kg}$. The frequency response function (FRF) of the z-slide was measured with and without the TMDDs. Fig. 5 shows the measurement results. The receptance in $Y$-direction $G_{Y Y}$ of the z-slide at its natural frequency $62 \mathrm{~Hz}$ without the TMDD is $1.379 \mu \mathrm{m} / \mathrm{N}$. Utilizing the measurement results from the third section, 11 TTMDs with the total mass $7.5 \mathrm{~kg}(1.9 \%$ of the $\mathrm{z}$-slide) were tuned to have the identical natural frequency $60 \mathrm{~Hz}$. They were installed on the z-slide to mitigate its vibration. The maximum of the receptance of the $\mathrm{z}$-slide is reduced from $1.379 \mu \mathrm{m} / \mathrm{N}$ to $0.415 \mu \mathrm{m} / \mathrm{N}$ by $70 \%$. The damping effect of the TTMDs is excellent.

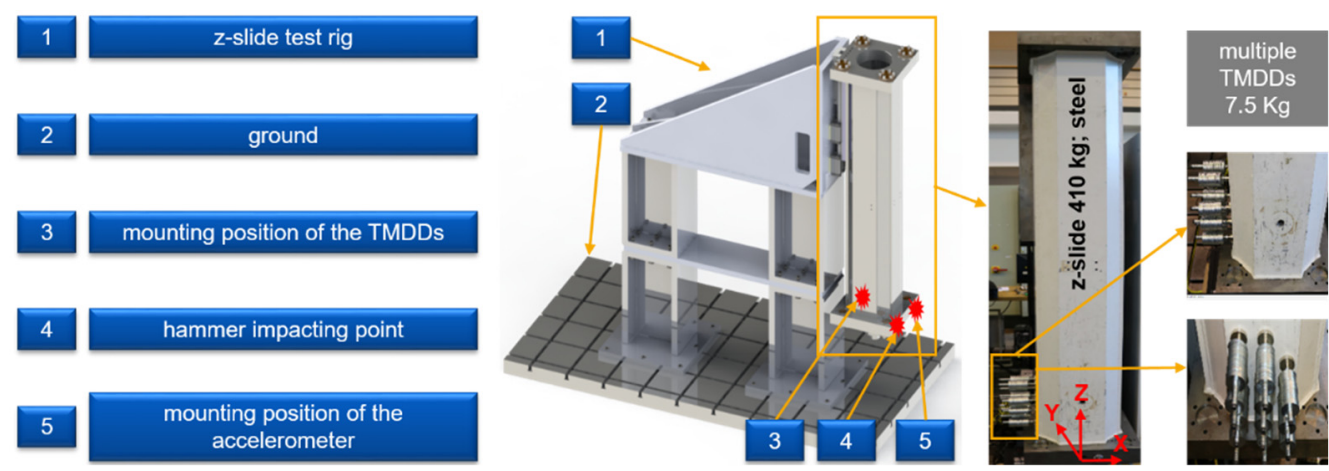

Fig. 4. Measurement set up for the validation of the TMDDs

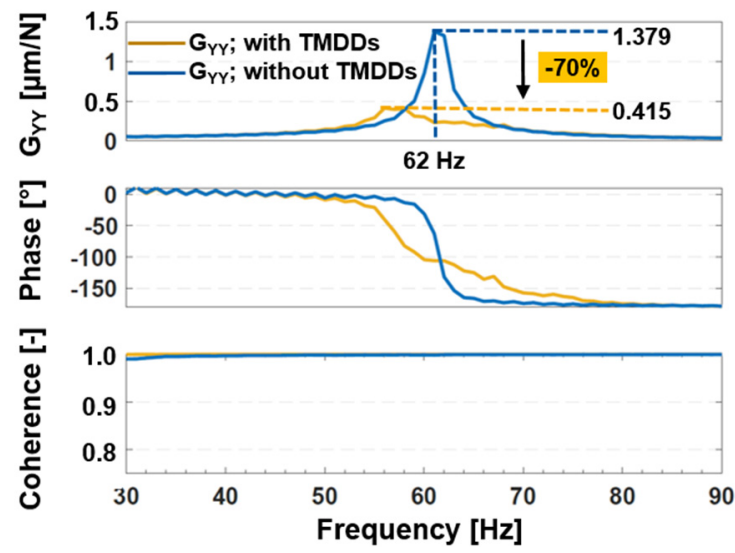

Fig. 5. Results of the impact hammer tests with and without the TMDDs

\section{Conclusions}

This paper presents a new passive vibration damper TMDD combining the merits of the TMD 
and the PD. The TMDD has three main advantages. First of all, the first natural frequency of the TMDD could be easily adjusted to match the critical natural frequency of the primary structure, whose vibration should be mitigated. Secondly, the damping effect is not generated from the viscous materials, but from the collision and the friction between the metal discs and the screw. This characteristic guarantees the robustness of the TMDD under the extreme environment temperature. Furthermore, the TMDD are installed through the magnetic foot, which means the threaded holes on the primary structure are not necessary. Because of the aforementioned advantages, the TMDD is very promising to avoid chatter during the metal cutting.

In the future research, the effectiveness of the TMDD will be validated by the cutting experiments. Furthermore, in order to better understand the vibration behavior of the TMDD, a mathematical or a physical model will be developed, which should calculate the natural frequency and the damping effect of the TMDD.

\section{Acknowledgements}

The authors would like to thank the German Research Foundation (DFG) for supporting this research under Grant No. BR2905/85-1: "Einsatz räumlich verteilter passiver Dämpfersysteme in einer Werkzeugmaschine".

\section{References}

[1] Taylor F. W. On the Art of Cutting Metals. The American Society of Mechanical Engineers, 1906.

[2] Munoa J., Beudaert X., Dombovari Z., Altintas Y., Budak E., Brecher C., Stepan G. Chatter suppression techniques in metal cutting. CIRP Annals, Vol. 65, Issue 2, 2016, p. 785-808.

[3] Frahm H. Device for Damping Vibrations of Bodies. United States patent 989,958, 1911.

[4] Hahn R. S. Design of Lanchester damper for elimination of metal cutting chatter. Transactions of ASME, Vol. 73, 1951, p. 331.

[5] Li S., Tang J. On vibration suppression and energy dissipation using tuned mass particle damper. Journal of Vibration and Acoustics, Vol. 139, Issue 1, 2017, p. 011008.

[6] Friend R. D., Kinra V. K. Particle impact damping. Journal of Sound and Vibration, Vol. 233, Issue 1, 2000, p. 93-118.

[7] Meyer N., Seifried R. Numerical and experimental investigations in the damping behavior of particle dampers attached to a vibrating structure. Computers and Structures, Vol. 238, 2020, p. 106281.

[8] Liu S., Lu Z., Li P., Zhang W., Taciroglu E. Effectiveness of particle tuned mass damper devices for pile-supported multi-story frames under seismic excitations. Structural Control and Health Monitoring, Vol. 27, Issue 11, 2020, p. e2627.

[9] Lu Z., Masri S. F., Lu X. Particle Damping Technology Based Structural Control. Springer, 2020. 